\title{
A Sociological Study of Transgression of Basic Guarded Rights of Transgenders \& Hurdles In Finding Their Gender Identity In Socio-Cultural Context (A case study of segregated localities of Multan)
}

\author{
Hina Aslam \\ M. Phil. Scholar \\ Department of Sociology, \\ Bahauddin Zakariya University Multan, Pakistan
}

\begin{abstract}
This article deals with the study of the problems faced by transgenders, in regards of their guarded rights being transgressed, both from the familial and socio-cultural context. This study is amid, to explore socio-cultural behavior of individuals who surround a trans either from his/her family or society. Questions have already emerged about sociological problems and cultural adjustment as a human being and its related casual factor related to a transgender. It is one of the emerging issues of our society that directly influences the identity of those people who are facing gender disapproval from their surroundings. This research work tried to discover the factors that influence the discrimination faced generally and particularly by trans. The article reveals the social and cultural norms that stigmatize socio-cultural exclusion of trans human beings from the society and how continuous banishment from society makes their life more tough after being rejected from their home/family. The present study analyzed the continuous deprivation of trans people rights from family to community having no secure rights of education, health and professional life conducting interviews from a group of trans residing in segregated areas of Multan, Pakistan. The findings also revealed the consequences of banishment, throws their life away from mainstream of a life a normal human being must have. The data in this paper has been collected by using qualitative research technique with participant observation and in-depth interviews.
\end{abstract}

Keywords: transgender guarded rights, socio-cultural problems of trans identity, stigmatization of gender identity, social exclusion of trans, gender deviance and deprivation of rights. 


\section{Introduction:}

Transgender" is an umbrella term that describes people whose gender identity or expression does not match the sex they were assigned at birth. For example, a transgender person may be identified as a female despite having been born with male genitalia. Transgender people have a gender identity or gender expression that differs from their sex assigned at birth. Some transgender who desire medical assistance for transition from one sex to another, are identified as transsexuals (shah and Rashid et,all 2017) . In Pakistani societies, transgender and trans -sexual have very little reorganization because we are taught to believe in typical binaries of male and female genders. An umbrella term that covers a different gender deviance is "Hijaras" that is commonly used for transgender in Pakistan. This terms covers those who bend away from common societal stereotypical role of gender that includes cross dressers, homos, bisexuals, transsexuals, transvestites, drag queens and transgender (Abdullah,et,all 2012). Transgender in Pakistani communities is a simple term about a person who don't know about gender identity and gender role and behaviors. People do not consider them as normal human being and people make fun of them. People from the society and even their own family members consider them as symbol of shame although they share the same parents as do their siblings. They do not want to meet them, or want to spend time with them despite of the fact that now they are recognized as equal citizens of Pakistan and human beings (Fatima\&ferdous et,all 2017). In conventional societies of Pakistan the life of transgender is miserable, friendless and unsafe. Stigmatized role and cultural recognition as different human beings leads to a terrible misbehavior of people toward them also causing sociopsychological issues for transgender. The rights of transgender have severely been violated since forever.

Because of this, transgender usually become the victim of sexual harassment and many of them are turning themselves in sex workers (Rayan \& futterman 1997). The status of transgender is very low and they are deprived from their basic guarded rights both from their parents and society. People uses the term 'hijras'is an abusive term abusive, in order to call someone a coward.. Transgender people experiences extreme anxiety, depression, self harm/suicide, prejudice, discrimination and extreme hostility from their family relatives and society (Mallon,1999). Transgender as children are usually excluded 
socially and also from their own family members, because they consider them a cause of disgrace and stigmatization for their whole family. Transsexuals live a very disturbing childhood because the demand and battle for their identity among their family and siblings which is always haunting their conscious and subconscious practices. Most of the children spend their early childhood with their family where they start to show a different behavior based on gender identity and get scolded from the family. At this age they start to feel prejudice and the unintended behavior from their family in form of formal and informal psychological and physical reprimands (Abdullah,et,all 2012). A transgender whose personal identity is not confirmed and is different from male and female gender, is always controversial for them to get their basic guarded rights. In Pakistani the sociocultural background, a transgender depicts a very different role in festivals including marriage ceremonies, birthdays, Eid festivals and other big events. Transgenders make up a group of people who have the lowest degree of rights and honor in Pakistan. Because of their low social acceptance in society and aggressive mind set of people surrounding them, they are not accepted as human being and almost from all part of Pakistan they face utter ignorance and rejection in almost all basic rights as citizens( Saddique et,all 2017).

\section{Research questions:}

- What is the socio-cultural behavior you have faced as a transgander from your family /relatives, since your consciousness?

- What are the socio-cultural elements that make a transgender getting marginalized and is left to survive on their wits, by a society?

\section{Assumptions}

The research got started by the researchers many assumptions about their particular study and those of which were researcher's own point of view. Given below are the main assumptions, that suggested the particular type and modal of the research exploration;

- The society may lack any cultural norms to be able to make a transgender a healthy/normal individual of the society.

- Families of transgenders might be forced by the pressure of society as well the relatives, to provide their trans child with his/her basic rights. 
- It may thought to be taboo for a society to accept the transgenders as a part of normal society.

- There may have not been a healthy educating system for us to treat transgenders as equal human beings.

- There may not be enough examples of progressed individuals of any transgenders or trangender groups in society to motivate a transgender willing to survive in a society, to get his/her guarded rights.

\section{Significance}

Particularly in state of Pakistan there is not enough discussion and research about providing the guarded rights and deal with a normal behavior both from the families having transgender individuals and the society the transgender faces and has to live to live in. The trangenders have never been treated as human in societies like we live in. No transgender has ever been treated equally or basically even as a human being. They even get killed by, in the name of honor in families who do not know how to introduce their trans individual or deal with the hate their trans individual is going to face by society. This study is significant because there rights and problems have never been addressed even as normal human being.

Third gender or transgender when born in families, initially after their gender being revealed, at a glance the families either throw them away or become hyper and feel ashamed. Some might attempt to kill them or to disown from their circle. The most important aspect of a transgender's life is perhaps the gender identity that determines the psycho-social behaviors of humans around them. This issue leads a human being not only to a problematic social life but also damages the self-esteem of individual that brings alienation and anomic condition to a trans. This study is significant to bring awareness among people for the rights of trans and highlight their issues. It is also significant for researchers and government for policy making and protection of trans rights.

\section{Local of the study}

The local of the present study is Multan city, Punjab. It is fifth largest city of Pakistan and has an Area of 133 squares kilometers. This city is also known as the "City Of Saints". The population of Multan estimated in 2017 is $\mathbf{1 . 8 7 2}$ millions, where people 
from all communities live. The current study is conducted in segregated localities of transgenders. The main areas where the trans mostly live and the researcher went into are Mumtazabad market, Gulgust market, Gulshan market, where selected interviews responded. Most of the transgender occupy those areas.

\section{Methodology:}

The qualitative research method is used in this research. Participant observation was used to explore the experience of transgender in the context of socio-cultural problems encountered by them who live in segregated areas of Multan.. In the present research the researcher explored the reality of problems faced by transgender for getting basic guarded rights in social and cultural perspective. Six cases were selected through purposive sampling technique and interviews were scheduled to built and collect data. Primary data was collected by participant observation and secondary data was collected by conducting in depth interviews. For phonological tradition in context to explore the lived experiences of transgenders, snowball technique was also used in order to conduct in depth interview with their family, gathering deeper information regarding their guarded and regarding study variables. Data was collected to semi structured interview that includes open ended question.

\section{Results and Discussions}

\section{Parental perception and guarded rights:}

The present study was investigated by in depth interviews and case studies of respondents that may varies from person to person. These interviews provide the need for investigation, further qualitative research through focus group discussion and inductive reasoning.

This study investigated the relationships among parental support, quality of life, and depression in transgenders lives. Family support is protective against victimization and bullying. Its also helps them to survive in this society. Because of parental support they feel less rejected in the society. Parental support was significantly associated with higher life satisfaction, lower perceived burden of being transgender, and less depressive. Because of parents support their quality of life is better. But despite of all these facts the study reveals this famous concept that the "guru" the one who leads and guards this 
community demands or snaps the custody of child who is born with ambiguous gender and genital. Most of the children spend their early childhood with their parents and family. Results show that most of the transgenders got to know about their being someone different from the pattern when their family actively started to abuse them, beat them down and taunted them for not being normal and disgraceful according to them.

In the lives of transgenders, how their family and siblings treat them is important. Unfortunately, it's quite normal here that their families do not accept them. There sibling victimize them because of being transgender, also facing bullying in the family. In their childhood trans people feel discriminated among their siblings and kins. At family gatherings, different festivals and occasions siblings and other relative member of the family try to keep them away from themselves, and treat them with different narratives. As far as the guarded rights of trans are concerned, they have none in the family. They are deprived and often times excluded from every gatherings. Their family members, relatives an kins don't let their children to play with them for they might catch their weird habits. These children are socially deprived from their basic rights, being members of family because they are considered and stigmatized as symbol of disgrace and shame for their family. Many respondents claim that they have very disturbing childhood in their early consciousness where their battle of gender identity is always hunting.

As Nazir \& Yasir (2016), argued that in such a scenario, verbalizing one's trans-identity to others can disrupt the social status of the family. More importantly, in a patriarchal society, like Pakistan, a male-to-female transgender has a particularly difficult path because it is reprehensible to identify and express a lower status when everything in the culture praise and support performance of duty and seeking a higher status Further, beyond the nuclear family, kinship network is another significant element of the society in Pakistan which serves as a support network and a safe environment for the reinforcement of socio-cultural practices. However, in such a closely-knit community it would not be possible for someone to maintain private boundaries. 


\section{Initial Family Behavior (early childhood as trans)}

Born with a sign of gender that is not really defined, the families of trans do not accept them as they do their off springs, having well defined gender. Initially they are, in most cases identified as boys in society. As the interviews of many reveal, they are treated as boys by their families. They are admitted in schools as boys. But they don't get the affection and love from their parents as equal as their siblings. This study revealed that discrimination and victimization of an insecure life comes from trans family itself. The mother and sisters are generally more affectionate and caring toward them although not always. But in typical patriarchic, such a born like that are considered a symbol of family shame. In their miserable journey of dealing with physical abuse, hatred, discrimination and the feeling of indifference, the trans have always suffered searching for a normal life, never knowing why?

\section{Case study}

Multan is city having patriarchal cultural and trading hub of southern Punjab. A respondent revealed that he was born in a well off family and his father owned a renown departmental store, during the interview ; "I was initially named as a boy. I was dressed as a boy and went to school with my other two bothers. But the time my father would had played and loved my brothers, he would jerked me off if I'd try to get closer to him. He'd never wanted to see me when I was at home. At the age of 11, I left my schooling and went with my elder brother at my father's departmental store. But he always felts insecure and had me getting bullied from other workers. My father always scolded me and consider me as symbol of shame. I remained with my mother because she was the only one who did not treat my any less than a human(like a mother usually treats her baby). She never made me feel like I was someone different, until the time I had to make the decision to leave home at my adult age."

According to him sometimes he tried to contact his father and asked about financial support but his father didn't give him any right in his property or any financial support. 
The study shows their struggle for their right and identity made their family betrayed them from their basic institution.

\section{Joint Family System Exposure and Effect}

One of the main reasons why the rights of trans are transgressed by their parents is the exposure of third gender to a joint family. A transgender born in a joint family faces quite a bad behavior initially from his/her relatives before stepping into the society. The parents of a trans feel immense pressure from their relatives as they try to treat their trans off spring equally to the others. It is showed from the relatives that giving birth to a child, that belongs to the different side of the pattern, is something shameful and disgraceful. Trans children belonging from joint family system revealed in the study that if they were to be received affection from their parents the family members never liked it because they didn't consider such disgrace (according to them) as a part of their family. The misbehavior of family members toward a trans, affected the parental behavior toward their trans child.

\section{Case study}

A trans respondent reveals that she was initially identified as boy after birth. She did go to the school with her siblings. But her family didn't bring her out with them whenever they go out for weddings, festivals and ceremonies. Even if her mother wanted to, her uncles forced her father to not to bring her with them. Her father never showed affection to her because her relatives within the family made him believe that her existence within the family is shameful. They owned a general store back when she was living with her family. She never knew why everyone within the family treated her differently and badly. It was unfamiliar to her why she was subjected out of the family in front of the society. She used to get beaten sometimes from her uncles for no reason. She worked there with her father and uncles and was mistreated all the time-used to get abused and sometimes got slapped for no reason at all. It was a worker there, who told her about "hijras" and then she came to know that there is a different society for this different sex. Tired of all this behavior she found it a little relieving that there is finally some place to accept her as human being. Now she begs in the day and goes to some functions with her guru and fellow members, trying to meet both her ends, earning very little. She sometimes feels the 
urge to see her parents and siblings but she doesn't want to them to be ashamed of her. Because she is quite relieved about the fact that she is no more a symbol of shame and disgrace for her family.

This interview shows how much difficult it is, living in a joint is being a trans, getting stigmatized by their blood relatives. Giving the trans their true and basic rights gets marginalized as taboo by their very own people(family).

\section{Stepping the Conscious Stage (Reaching a Specific Age)}

While being born as trans but still getting assigned a gender, a transgender actually starts to feel the misbehavior he/she faces from their family when reaches a particular conscious level. Early childhood passes by without realizing that they don't belong the category they were assigned since birth. Now when they come to know why they are marginalized, hidden and kept inside almost all the time when other fellows of the same age are living an entire different life. The participants revealed that they never knew they why they were being treated in a different way until stepping in consciousness.

One of them revealed "I was a normal boy as I played with boys of my age in early childhood. Sometimes they would bully me saying I don't belong with them and that I was a "khusra". My sisters played with at home but never did my brothers. My father and uncles were affectionate toward my brothers but not me. I never felt this behavior until the time I was conscious and I realized I was treated wrong even though I still don't know why? I felt heavy and so bad with this discrimination from my family but I did not what to do to make them love me as they did my other siblings. But I sure knew I was a burden and somehow an utter disappointment to them and that shattered my confidence all along."

\section{Stigmatization Leading a Consequent Banishment from Society:}

The perspective of this article was to find out the role of society regarding the transgression of transgender rights. One of the causes of discrimination and indifference of trans, indulging and forcing them to leave their families and to live with the specified community in segregated localities with social stigma includes how the society marginalizes them. The findings of the study provide evidence that this sexual minority 
feel extreme discrimination and victimization of socio-psychological form of abuse, from their basic institution toward society. This current finding tells a lot about the cognition prevailing in society regarding a different gender makes trans alienate as being normal human being of society. Unfortunately, even if the families of transgender support them that is actually very rare, the society won't. There are some transgenders that exposed that their families went on supporting them with the assigned gender. But stepping into society, getting marginalized and stigmatized forced them not to be active members of the society. They did went to schools but because of their body gestures and some time physical appearance revealed their gender identity. From classmates to teachers and office boys they all started to feel insecure because everyone they interacted with, was trying to molest them.

As SaleemNH et,all (2008)argued institutional discrimination and indifferences, physical and verbal abuse and stigmatization of different abusive taunts forced sexual intention and having no support from their family and society all have very strong effect on risky attitude has severe sort of impact of suicidal adaptation, drug abuse and selling sex among trans community.

It was revealed during indepth interview with respondents that since from their early childhood there remains a personality development gap, because of the fear being of physically discriminated and ridiculed with in family and surrounding, that made them not to go to schools and work in community like normal human being.

Most of the" hijras "in segregated localities of Multan have no occupational opportunities. Most of the respondent despite of belonging to wealthy families, they are living with their specified community because of forced socio cultural stigmatized rule. Most of the transgender, meet their both ends by dancing, in different festivals and gatherings, some are professional beggars and many are compelled to be commercial sex worker. It has been observed from different studies having no support from their family and relatives. .Discrimination and prejudice from community members can be the biggest reasons of tran being socially excluded, pushing them toward a risky behavior of commercial sex working, begging, drug abuse and potential tendencies toward sucide ( Khan SI,et all 2009 , Ahmed et,all 2014). 


\section{Socio-Cultural Barrier : A Life Away From Mainstream}

In this qualitative research study researcher tried to get more information about the barriers a trans faces while living through severe misery in the socio-cultural background. It is one of the burning issues of our society and directly interacts with bounderies derived by the society that do not haveany ethical or lawful base.. The findings revealed a lot about them being deprived from their basic individual rights in normal in sociocultural perspective that throw them away from their role in normal mainstream of life. As a participant observer it, poor living and health facilities were observed in almost all trans communities. Discussion with one of the respondents revealed that they face housing instability and because of the discrimination they face at govt hospitals, where they are overlooked being trans, lacking poor health facilities. Transgender as a stigma of dishonored gender,in cultural patterns, have impressions of providing of cheap sex. Even with this labalization, most of the times they are treated utterly bad by people who use them. Sometimes they are punished or even shot dead because their lives don't matter to anyone. One of them stated "Sometimes, we feel lucky to be back at home safely, without bruises or any other severe tackle because of most of the times it's normal for the ones who pay us a little money, to beat us or kill us if they like it. We aren't paid much. Just with a little money that merely buys us food for two times Some people do not even pay us sometime and if we ask for it, they give us death threats because they know we have nowhere to go and no one to complain to". Trans are compelled to live in congested red light areas with their guru in small rooms while working as sex workers. Moreover respondents revealed that they have always felt a typical mocking behavior since from their home because of prevailing myths and stereotypical role and cognitions cultural settings leads discrimination in every walk of live. Despite of all mentioned facts, some transgender are scared to visit health professionals. One of the respondents revealed that they are not take as seriously as others. However other respondents said that they are used to the behaviors of people so they are okay with health care professionals.

Gordon et,all(2000) argued that socio-cultural barriers are carried by following indicator of social-exclusion: difficulties in earning in household, having difficulties to meet basic needs, disadvantages of poor housing conditions, poor self perceived health status, 
infrequent contacts with friends and family, not properly getting work in occupation and labor are the main problems encountered.

Keeping these indicators in overall research it was revealed that trans-community in Pakistan, because of social exclusion they are dealing with, are deprived from their basic guarded rights since their childhood. Because of uneducated and aggressive mind set people in these societies, they do not prompt to accept them as human beings of Pakistani society

\section{Conclusion:}

Surrounded by conservative social structure and institutions where there is less space for gender minority in social, cultural and political sphere of life, it is never easy for trans to get their rights smoothly. Educational, health and occupational services are extremely constrained for a person having trans identity. In hierarchal social status, they are considered abnormal and ultimate outsiders from their family-their basic human rights being violated severely. As a Pakistani transgender, walking away from the family is not possible, as you are recognized through the family name in the end. These transgenders are neither allowed to live in a family nor allowed to live with their free will on their own as they are frightened to be the cause of dishonor to their family name. They face serious life threats from mobs, commonly existing in such societies because their life does not matter at all.

A trans-gender is a biological change which makes people, to behave differently from the stereotypes of males and females. Because of this biological change, they are excluded from society which should be eradicated. They face discrimination, different treatment which is unbearable for any human being in general, and undue attention in their each and every phase of life. Transgenders in Pakistani society are considered as a shame for their family and are condemned by the family members. Parents should strive to create a positive atmosphere within the home. This can be achieved by encouraging open communication amongst the family member. There is a need of basic legislation on transgender on transgender issues in all institution to accept them as basic human right, especially within family as basic unit of life. Awareness campaigns and seminars must be 
planed by policy makers to bring it to the notice of each responsible member of the society, to treat them as normal human beings in mainstream of life and to ensure their guarded rights. Policy makers and law making firms should bring them as need of society through participatory approach. Awareness campaigns seminars and workshops should be conducted by government in gross root level in the presence of third gender, for the consideration of normal human being without any prejudice. 


\section{References}

1. Saddique, K. A. M. R. A. N., Mirbehar, S., Batool, H., Ahmad, I., \& Gang, C. (2017). Transgender issues in Pakistani community. European Academic Research, 4(10), 9048-9057.

2. Saleem, N. H., Adrien, A., \& Razaque, A. (2008). Risky sexual behavior, knowledge of sexually transmitted infections and treatment utilization among a vulnerable population in Rawalpindi, Pakistan. Southeast Asian J Trop Med Public Health, 39(4), 642-8.

3. Khan, S. I., Hussain, M. I., Parveen, S., Bhuiyan, M. I., Gourab, G., Sarker, G. F., ... \& Sikder, J. (2009). Living on the extreme margin: social exclusion of the transgender population (hijra) in Bangladesh. Journal of health, population, and nutrition, 27(4), 441.

4. Ahmed, U., Yasin, G., \& Umair, A. (2014). Factors affecting the social exclusion of eunuchs (hijras) in Pakistan. Mediterranean Journal of Social Sciences, 5(23), 2277-2277.

5. Nazir, N., \& Yasir, A. (2016). Education, Employability and Shift of Occupation of Transgender in Pakistan: A Case Study of Khyber Pakhtunkhwa. Dialogue (Pakistan), 11(2).

6. Abdullah, M. A., Basharat, Z., Kamal, B., Sattar, N. Y., Hassan, Z. F., Jan, A. D., \& Shafqat, A. (2012). Is social exclusion pushing the Pakistani Hijras (Transgenders) towards commercial sex work? a qualitative study. BMC international health and human rights, 12(1), 32.

7. Mallon, G. P. (1999). A glossary of transgendered definitions. Journal of Gay \& Lesbian Social Services, 10(3/4), 143-145.

8. Ryan, C., \& Futterman, D. (1997). Lesbian and gay youth: care and counseling. Adolescent medicine (Philadelphia, Pa.), 8(2), 207.

9. FATIMA, H., FERDOUS, A., QADIR, A., \& RASHID, A. (2017). GENDER INDISTINCTIVENESS: PSYCHOLOGICAL PROBLEMS AND THEIR ASSOCIATED CAUSAL FACTORS AMONG TRANSGENDER OF PAKISTAN. Pakistan Postgraduate Medical Journal, 28(1), 31-37.

10. Abdullah, M. A., Basharat, Z., Kamal, B., Sattar, N. Y., Hassan, Z. F., Jan, A. D., \& Shafqat, A. (2012). Is social exclusion pushing the Pakistani Hijras (Transgenders) towards commercial sex work? a qualitative study. BMC international health and human rights, 12(1), 32.

11. Shah, H. B. U., Rashid, F., Atif, I., Hydrie, M. Z., Fawad, M. W. B., Muzaffar, H. Z., ... \& Hassan, A. (2018). Challenges faced by marginalized communities such as transgenders in Pakistan. The Pan African Medical Journal, 30. 